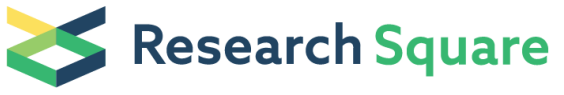 \\ Preprints are preliminary reports that have not undergone peer review. \\ They should not be considered conclusive, used to inform clinical practice, or referenced by the media as validated information.
}

\section{Sensorimotor and Body Perception Assessments of Chronic Nonspecific Low Back Pain: A Case-Control Study}

\author{
Meier Raphael \\ Prodorso \\ Christine Emch \\ Physiotherapie Schutzengel

\section{Claudia Wolf} \\ Physiotherapie Sonnenheim
}

\section{Fabian Pfeiffer}

Zurich University of Applied Sciences School of Health Professions: Zurcher Hochschule fur Angewandte Wissenschaften Departement Gesundheit

\section{Andre Meichtry}

Zurich University of Applied Sciences School of Health Professions: Zurcher Hochschule fur Angewandte Wissenschaften Departement Gesundheit

\section{Annina B. Schmid}

University of Oxford Nuffield Department of Clinical Neurosciences

Hannu Luomajoki ( $\square$ Hannu.luomajoki@zhaw.ch )

Zurich University of Applied Sciences https://orcid.org/0000-0002-8023-4805

\section{Research article}

Keywords: chronic nonspecific low back pain, back-photo assessment, movement control impairment, two-point discrimination

Posted Date: December 1st, 2020

DOI: https://doi.org/10.21203/rs.3.rs-114590/v1

License: (1) This work is licensed under a Creative Commons Attribution 4.0 International License. Read Full License 


\section{Abstract}

Background: Low back pain is one of the most common musculoskeletal disorders. It leads to major costs in health care systems and causes significant personal and social burdens. Current research focuses on the processes of the central nervous system such as cortical changes in pain perception to discover new and more efficient ways to treat chronic low back pain (CLBP). Several clinical tests have been suggested that might correlate with altered cortical representation. These include back-photo assessment (BPA), movement control tests (MCl) and two-point discrimination thresholds (TPD).

Objective: The aim of this study was to determine whether BPA, MCI and TPD tests can discriminate between CLBP patients with altered body perception and healthy controls.

Design: A case-control study matched by gender and age.

Methods: Using MCl, BPA and TPD tests on the lower back, thirty patients with CLBP and thirty healthy controls were investigated at one point in time. Participants were also required to complete three questionnaires: the 'Fear Avoidance Belief Questionnaire', the 'Hospital Anxiety and Depression Scale' and the 'Fremantle Back Awareness Questionnaire'. Correlations among the main covariates and odds ratios for group differences were calculated.

Results: The MCl showed a statistically significant odds ratio for the presence of CLBP of $0.65(p<0.05)$, whereas TPD and BPA did not determine differences between the groups.

Conclusion: The movement control test was found to be the only suitable test to discriminate CLBP patients from healthy controls.

Trial registration: The study was approved by the Swiss Ethical Commission Northwest and Central Switzerland (EKNZ) and registered at 21.8.2015, reference number 2015-243.

\section{Introduction}

Low Back Pain (LBP) is one of the most common musculoskeletal disorders and causes significant personal and social burdens (1). LBP has a lifetime prevalence of $70-85 \%$ (2). Although the prognosis for recovery from acute LBP is favorable, recurrence is common, with $33 \%$ reporting a renewed onset of LBP within one year (2). Furthermore, 42-75\% continue to experience LBP 12 months after pain onset (3). When LBP becomes persistent it creates major costs in health care systems (4). Currently, $85 \%$ of LBP cases are classified as nonspecific LBP, meaning that no specific structural causes can solely explain the symptoms (5). Strategies to manage nonspecific LBP include both conservative and invasive treatments. Outcomes for unimodal treatments are poor (1). Thus, tailored management strategies for LBP treatment remain a major challenge (6-8).

Chronic LBP is defined pain longer than 3 months (9). Recent neuroimaging studies have demonstrated neurochemical, structural and functional alterations in the primary sensory cortex in these patients $(5,7,8)$. This supports the emerging evidence that central nervous system (CNS) processes also contribute to $\operatorname{CLBP}(7,10)$. CLBP may increase sensitivity in the spinal cord and the cortex, leading to the amplification of peripheral inputs and, possibly, causing widespread hyperalgesia. Furthermore, the inhibitory mechanisms of the CNS demonstrate reduced functionality in CLBP patients $(8,10-12)$. These factors may contribute to the previously identified changes in cortical representations and body perceptions, as well as reduced grey matter volume in the somatosensory cortex $(8,10-12)$. As such, simple clinical tests to assess the sensory motor system and develop tailored management strategies for patients in a chronic pain state, have become increasingly important to physicians.

Several clinical assessments are thought to be correlates of changes in sensory and motor system and body perception on a cortical level. Firstly, two-point discrimination (TPD) examines the tactile acuity of LBP patients. Patients with LBP demonstrate increased TPD values compared to healthy controls $(13,14)$. TPD was proposed as a surrogate measure of changes in the somatosensory cortex $(\mathrm{S} 1)(11,15-$ 17). Secondly, CLBP patients present with reduced perception of their spine (18), affecting movement that is controlled by the central nervous system $(12,19)$. Tests of movement control impairment $(\mathrm{MCl})$ are common in identifying possible deficits of motor control $(20,21)$ and can discriminate between LBP patients and healthy controls (12, 18-21). MCl and TPD are associated (17) Thirdly, visual approaches, such as back-photo assessment (BPA), can test body perception and perceived body image. BPA uses photos to modify the width of the person's lower back. People are asked to identify the original, unmodified photo of their back from the various modified versions. This method has already been used on limbs in patients with complex regional pain syndrome (CRPS) is thought to present changes in S1(22). However, to date, BPA has not been validated for CLBP patients. Recent evidence has demonstrated an altered body image perception in 
patients with CLBP when asked to complete a partial drawing of their back silhouette. CLBP patients were unable to clearly outline their trunk in the painful area (23).

The aim of this study was to determine whether BPA, MCl and TPD tests which are thought to present somatosensory changes, could discriminate between CLBP patients with altered body perception and healthy controls.

\section{Methods}

\section{Participants}

A convenience sample of 60 participants was collected from three outpatient physiotherapy clinics in Central Switzerland. Thirty were patients with nonspecific CLBP, 30 were controls and the groups were matched by gender and age. Inclusion criteria were: 1) age between 18 and 83 years; 2) proficient in written and spoken German language; 3) no current pregnancy or pregnancy in the past 6 months; 4 ) at least four points on the Roland Morris Disability Questionnaire (RMDQ) indicating at least moderate disability because of LBP; and 5) the presence of CLBP as defined by at least three months of unilateral or bilateral LBP. CLBP participant exclusions were: 1) clinical bedside signs of nerve root pain or evidence of specific spinal pathology (e.g. malignancy, fracture, infection, inflammatory join or bone disease and 2) surgery on the lower back in the past six months. Healthy controls were excluded if they had any history of LBP in the past six months or a period of LBP of more than one month in the past. The Swiss Ethical Commission of Northwest and Central Switzerland (EKNZ) ethically approved the study (reference number 2015 - 243). All participants gave their informed written consent prior to study start and all procedures conformed to the declaration of Helsinki.

\section{Design}

Case-control study design.

\section{Assessments}

Examiners were blinded to the participants' condition and recorded the results of the BPA, TPD and MCI tests.

BPA is a graphic approach to exploring distorted body image. It has previously been used to assess a population with complex regional pain syndrome (CRPS) (22). In this study, the lumbar vertebra four was marked on the skin and a photo taken in a standing position from the middle part of the gluteal area to the occipital part of the skull to depict the participant's back. The photo was then modified at level L4, using the GNU Image Manipulation Program (GIMP 2.8.14 for OS X) in steps of 3\% enlargement and shrinkage. The maximal limit was set at $\pm 12 \%$. This resulted in eight modified photos plus one original photo for each participant. The photos were allocated a number from 1 to 9 in order of the modification extent. Numbers 1 to 4 were allocated to the shrunken photos with 1 representing picture shrunk by -12\% (Fig. 1). Number 5 was given to the original, unmodified photo and numbers 6 to 9 were allocated to the enlarged photos, with 9 representing the picture enlarged by $12 \%$. The photos were then arranged on a piece of paper in a randomized sequence. The same sequence was used for all participants. The participants were asked to identify the original photo of their back. The number of deviating steps between chosen and neutral picture, no matter if to the shrunken or enlarged direction, was noted as BPA outcome with a value ranging from $0-4$.

TPD is a reliable intra-rater measure to detect altered tactile acuity (24). TPD measurements were taken using a plastic caliper, according to an established protocol $(15,17,25)$ (Fig. 2.). The participant lay prone and unable to see the caliper. An examiner measured both horizontal and vertical TPD bilaterally on the participant's lower back at level L4 (24). The caliper tip distance ranged from $100 \mathrm{~mm}$ to $5 \mathrm{~mm}$, and the test started with the maximum spread. For every correct detection, the spread distance was decreased by 10 mm. Conversely, for every incorrect detection, the spread distance was increased by $5 \mathrm{~mm}$. This procedure was repeated three times in descending and ascending order and the average of the smallest distance between the caliper tips at which the participant was still able to discriminate between the two separate points was recorded as the TPD value (17).

$\mathrm{MCl}$ of the lumbar spine was evaluated using a test battery of six tests designed to test the movement control of the back (Fig. 3.). The $\mathrm{MCl}$ test battery has been shown to be a reliable tool to detect impaired lumbopelvic control $(20,21,26)$. Firstly, the examiner explained the task and the participants were instructed to perform specific movements. Secondly, the examiner provided verbal corrections if the movement was performed incorrectly. Finally, if the movement was performed incorrectly at the second try, the examiner demonstrated the correct movement. A positive test result was recorded if a participant was still unable to perform the correct movement following the second demonstration. Examiners rated a correctly performed movement as a negative test result. The test results were scored on a range from 0 (all tests performed correctly) to 6 (no test performed correctly) and these served as the outcome values for $\mathrm{MCl}$. A detailed description of the $\mathrm{MCl}$ test battery and the definition of ratings can be found elsewhere (20). 


\section{Questionnaires}

Basic demographic and clinical data were obtained from all participants. The Roland Morris Disability Questionnaire (RMDQ) (30) was used to screen for eligibility. Subsequently, participants answered the Fear Avoidance Belief Questionnaire (FABQ) (31), Fremantle Back Awareness Questionnaire (FreBaQ) (32) and Hospital Anxiety and Depression Scale (HADS) $(33,34)$. These questionnaires have been validated in the German language.

In addition, CLBP subjects were asked to report the locality of their pain (bilateral, left-sided or right-sided), its duration and mean intensity using a visual analogue scale (VAS). This scale ranges from 0 (no pain) to 100 (worst pain) (35).

\section{Statistical analysis}

All statistical analyses were performed using R (version 3.2.3) (36). Normality of data was determined by inspection of histograms. Demographics, questionnaire data, BPA, TPD and $\mathrm{MCl}$ were analyzed with descriptive statistics. Spearman correlations were used for all variables. We applied multiple logistic regressions with conditional likelihood to determine associations of the main outcomes (BPA, TPD and $\mathrm{MCl}$ ) with the presence of CLBP. The log odds of the presence of CLBP were modelled with six covariates. These covariates were BPA, $\mathrm{MCl}$ and TPD (left and right horizontal TPD, left and right vertical TPD). The objective was to quantify the effect of each covariate on the outcome CLBP.

\section{Results}

Apart from Body Mass Index (BMI) which was higher in the CLBP group, the demographics of both groups were similar at baseline (Table 1). Table 2 illustrates the results of the assessments outcomes. BPA and TPD values were similar for both groups. Table 3 summarizes the results of the multiple logistic regression analysis. Significant between-group differences could be demonstrated for $\mathrm{MCI}$ only, with a statistically significant odds ratio of 0.65 for $\mathrm{MCl}(\exp$ (coef) $1.92,95 \% \mathrm{Cl} 1.00-3.68)$ for the presence of CLBP. This means that for each point greater on the $\mathrm{MCl}$ test battery the odds of being a patient with LBP increases 0.65 times. This result was not found for TPD or BPA. No statistically significant correlations between the independent variables were identified (Table 4). However, the results of the FABQ and FreBaQ demonstrated large differences between the groups (Table 2).

\section{Discussion}

The main objective of this study was to examine the ability of three commonly performed clinical tests to discriminate between CLBP patients and healthy controls. Our results revealed discriminative ability for the $\mathrm{MCl}$ test, but not for the BPA and TPD tests. Consequently, we can only recommend $\mathrm{MCl}$ as a test for this discrimination, due to its statistically significant odds ratio of .65 for the likelihood of having LBP.

This finding for $\mathrm{MCl}$ confirms previous results, in which discriminative ability was found between LBP patients and healthy controls $(12,18-$ 21). Luomajoki et al. revealed a mean $\mathrm{MCl}$ score (out of 6) of 2.21 in patients with LBP and 0.75 in healthy controls (21). In contrast, both of our groups had higher $\mathrm{MCl}$ scores: 3.0 for CLBP patients and 2.0 for healthy controls. However, this current study only included patients with CLBP, whereas Luomajoki et al. also investigated patients with acute and subacute LBP (21).

Our results for the BPA test differ from previous research. Moseley et al (2005) used a similar approach with CRPS patients, demonstrating that patients selected photos with a 7\% enlargement of the original size in the chronic pain group (22). In our study, both CLBP patients and healthy controls tended to choose enlarged photos of their backs and showed no meaningful between-group difference. Our BPA results indicate no significant association between an increased BPA score and a higher chance of having CLBP. However, different enlargement steps used in the Moseley et al. study could partly explain the different results. Our photos were modified in $3 \%$ steps, whereas Moseley et al. used $5 \%$ steps. In contrast to our study, the latter also demonstrated a correlation between the chosen picture and the duration of symptoms (22). BPA is a rather novel test for the detection of altered body perception, based on only preliminary data for CRPS patients, but it has not yet been validated for CLBP patients. Furthermore, our study investigated the trunk, whereas Moseley et al. focused on limbs, showing pictures of their both hands to participants. In the Moseley et al. study, the affected hand was modified, thereby allowing a comparison of both hands. In contrast, we only showed modified photos of one area at level, L4. Hence, the results of the two studies cannot be compared directly.

Our findings for the TPD test also diverge from previous studies that demonstrated a discriminative ability of TPD between CLBP patients and healthy controls $(15,17,37)$. Luomajoki and Moseley also observed a correlation between the TPD and MCl tests (17). However, our study found no statistically significant correlation between TPD and MCI. Furthermore, no statistically significant correlations among the 
independent variables were found. This accords with previous research. Ehrenbrusthoff et al. questioned the correlation between TPD and the FreBaQ questionnaire, by doubting the similarity of the underlying construct (38). However, recent studies have demonstrated correlations between TPD and body image drawings, which is another visual approach similar to BPA $(23,39)$.

This leads to the question of whether low baseline pain intensity of 33.4/100 VAS and disability of 8.2/24 in our patient cohort, which may cause less alteration at the cortical level could explain the inability of the included tests to demonstrate significant discriminative capability. Nevertheless, it remains unclear as to whether higher pain intensities and disability levels would result in greater discriminative ability between CLBP and healthy controls.

A methodological limitation of this study was that two different assessors performed the assessment of TPD to maintain blinding of all assessors. Catley et al. (2013) questioned the inter-rater reliability of TPD at the lower back (24). Therefore, this could have influenced our results.

Additional research is needed to improve BPA.. We suggest that enlargement steps should be increased from $3-5 \%$ and that the impact of smaller increments on significance be investigated. It is also unclear whether CLBP patients with higher activity levels would have different outcomes to CLBP patients with lower activity levels. Research has shown a change of proprioception and, therefore, movement control due to exercise $(1,40,41)$. Moreover, a screening of the sample according to the criteria of the avoidance-endurance model of pain may result in more consistent findings.

\section{Conclusion}

We have investigated the ability of $\mathrm{MCl}, \mathrm{TPD}$ and BPA tests to discriminate altered body perception in CLBP patients. Only MCI was shown to be valid in differentiating between CLBP patients with low to moderate pain and disability levels and healthy controls. However, further research is needed to elucidate the potential of all tests to detect CLBP patients.

\section{Abbreviation List}

\begin{tabular}{|ll|}
\hline Back-Photo Assessment & BPA \\
\hline Body Mass Index & BMI \\
\hline Chronic Low Back Pain & CLBP \\
\hline Complex Regional Pain Syndrome & CRPS \\
\hline Fear Avoidance Belief Questionnaire & FABQ \\
\hline Fremantle Back Awareness Questionnaire & FrBaQ \\
\hline Hospital Anxiety and Depression Scale & HADS \\
\hline Low Back Pain & LBP \\
\hline Movement Control Impairment test & MCI \\
\hline Roland Morris Disability Questionnaire & RMDQ \\
\hline Swiss Ethical Commission Northwest- and Central Switzerland & EKNZ \\
\hline Two-Point Discrimination & TPD \\
\hline Visual Analogue Scale & VAS \\
\hline
\end{tabular}

\section{Declarations}

Ethics approval and consent to participate

The Swiss Ethical Commission of Northwest and Central Switzerland (EKNZ) gave ethical approval (reference number 2015-243) to the study. All participants gave their informed consent prior to study start and all procedures conformed to the declaration of Helsinki

Availability of data and materials

The datasets used and/or analysed during the current study are available from the corresponding author on reasonable request. 
The authors declare that they have no competing interests.

\section{Funding}

As a master thesis, there was no funding received for the study.

\section{Authors' contributions}

This article was developed equally be the first three authors. RM contributed to statistical data-analysis and writing. CE and CGW recruited and examined the participants and contributed to research plan, writing and statistical data-analysis. FP participated in statistical dataanalysis and writing. AM calculated the statistics for the study and was involved in the research plan. $\mathrm{HL}$ and $\mathrm{AS}$ were involved in the design of the study. HL contributed to examination of participants and writing. All authors read and approved the final manuscript.

\section{References}

1. O'Keeffe M, Purtill H, Kennedy N, Conneely M, Hurley J, O'Sullivan P, et al. Comparative Effectiveness of Conservative Interventions for Nonspecific Chronic Spinal Pain: Physical, Behavioral/Psychologically Informed, or Combined? A Systematic Review and MetaAnalysis. J Pain. 2016 Jul;17(7):755-74.

2. Stanton TR, Henschke N, Maher CG, Refshauge KM, Latimer J, McAuley JH. After an episode of acute low back pain, recurrence is unpredictable and not as common as previously thought. Spine. 2008 Dec 15;33(26):2923-8.

3. Hestbaek L, Leboeuf-Yde C, Manniche C. Low back pain: what is the long-term course? A review of studies of general patient populations. Eur Spine J Off Publ Eur Spine Soc Eur Spinal Deform Soc Eur Sect Cerv Spine Res Soc. 2003 Apr;12(2):149-65.

4. Nicholas M, Vlaeyen JWS, Rief W, Barke A, Aziz Q, Benoliel R, et al. The IASP classification of chronic pain for ICD-11: chronic primary pain. PAIN. 2019 Jan;160(1):28-37.

5. O'Sullivan P. Diagnosis and classification of chronic low back pain disorders: Maladaptive movement and motor control impairments as underlying mechanism. Man Ther. 2005 Nov;10(4):242-55.

6. Guzman J. Multidisciplinary rehabilitation for chronic low back pain: systematic review. BMJ. 2001 Jun 23;322(7301):1511-6.

7. Wand BM, O'Connell NE, Di Pietro F, Bulsara M. Managing Chronic Nonspecific Low Back Pain With a Sensorimotor Retraining Approach: Exploratory Multiple-Baseline Study of 3 Participants. Phys Ther. 2011 Apr 1;91(4):535-46.

8. Ebenbichler GR, E. Oddsson LI, Kollmitzer J, Erim Z. Sensory-motor control of the lower back: implications for rehabilitation: Med Sci Sports Exerc. 2001 Nov;33(11):1889-98.

9. Violante FS, Mattioli S, Bonfiglioli R. Low-back pain. In: Handbook of Clinical Neurology [Internet]. Elsevier; 2015 [cited 2019 Dec 9]. p. 397-410. Available from: https://linkinghub.elsevier.com/retrieve/pii/B9780444626271000202

10. Wand BM, Parkitny L, O'Connell NE, Luomajoki H, McAuley JH, Thacker M, et al. Cortical changes in chronic low back pain: Current state of the art and implications for clinical practice. Man Ther. 2011 Feb;16(1):15-20.

11. Moseley GL, Flor H. Targeting Cortical Representations in the Treatment of Chronic Pain: A Review. Neurorehabil Neural Repair. 2012 Jul;26(6):646-52.

12. Roussel NA, Nijs J, Meeus M, Mylius V, Fayt C, Oostendorp R. Central Sensitization and Altered Central Pain Processing in Chronic Low Back Pain: Fact or Myth? Clin J Pain. 2013 Jul;29(7):625-38.

13. Lotze M, Moseley GL. Role of distorted body image in pain. Curr Rheumatol Rep. 2007 Dec;9(6):488-96.

14. Catley MJ, Tabor A, Miegel RG, Wand BM, Spence C, Moseley GL. Show me the skin! Does seeing the back enhance tactile acuity at the back? Man Ther. 2014 Oct;19(5):461-6.

15. Wand BM, Di Pietro F, George P, O'Connell NE. Tactile thresholds are preserved yet complex sensory function is impaired over the lumbar spine of chronic non-specific low back pain patients: a preliminary investigation. Physiotherapy. 2010 Dec;96(4):317-23.

16. Wand BM, Catley MJ, Luomajoki HA, O'Sullivan KJ, Di Pietro F, O'Connell NE, et al. Lumbar tactile acuity is near identical between sides in healthy pain-free participants. Man Ther. 2014 Oct;19(5):504-7.

17. Luomajoki H, Moseley GL. Tactile acuity and lumbopelvic motor control in patients with back pain and healthy controls. Br J Sports Med. 2011 Apr 1;45(5):437-40.

18. Gill KP, Callaghan MJ. The Measurement of Lumbar Proprioception in Individuals With and Without Low Back Pain: Spine. 1998 Feb;23(3):371-7. 
19. Hodges PW, Moseley GL. Pain and motor control of the lumbopelvic region: effect and possible mechanisms. J Electromyogr Kinesiol. 2003 Aug;13(4):361-70.

20. Luomajoki H, Kool J, de Bruin ED, Airaksinen O. Reliability of movement control tests in the lumbar spine. BMC Musculoskelet Disord. 2007 Dec;8(1):90.

21. Luomajoki H, Kool J, de Bruin ED, Airaksinen O. Movement control tests of the low back; evaluation of the difference between patients with low back pain and healthy controls. BMC Musculoskelet Disord. 2008 Dec;9(1):170.

22. Moseley GL. Distorted body image in complex regional pain syndrome. Neurology. 2005 Sep 13;65(5):773-773.

23. Moseley LG. I can't find it! Distorted body image and tactile dysfunction in patients with chronic back pain: Pain. 2008 Nov;140(1):23943.

24. Catley MJ, Tabor A, Wand BM, Moseley GL. Assessing tactile acuity in rheumatology and musculoskeletal medicine-how reliable are two-point discrimination tests at the neck, hand, back and foot? Rheumatology. 2013 Aug;52(8):1454-61.

25. Moberg E. Two-point discrimination test. A valuable part of hand surgical rehabilitation, e.g. in tetraplegia. Scand J Rehabil Med. 1990;22(3):127-34.

26. Luomajoki H. Sechs Richtige: Mit der Testbatterie die lumbale Bewegungskontrolle untersuchen. $2012 ; 16$.

27. Jordan K, Dunn KM, Lewis M, Croft P. A minimal clinically important difference was derived for the Roland-Morris Disability Questionnaire for low back pain. J Clin Epidemiol. 2006 Jan;59(1):45-52.

28. Stratford PW, Binkley J, Solomon P, Finch E, Gill C, Moreland J. Defining the Minimum Level of Detectable Change for the Roland-Morris Questionnaire. Phys Ther. 1996 Apr 1;76(4):359-65.

29. Exner V, Keel P. [Measuring disability of patients with low-back pain-validation of a German version of the Roland \& Morris disability questionnaire]. Schmerz Berl Ger. 2000 Dec;14(6):392-400.

30. Roland M, Fairbank J. The Roland-Morris Disability Questionnaire and the Oswestry Disability Questionnaire: Spine. 2000 Dec;25(24):3115-24.

31. Staerkle R, Mannion AnneF, Elfering A, Junge A, Semmer NorbertK, Jacobshagen N, et al. Longitudinal validation of the Fear-Avoidance Beliefs Questionnaire (FABQ) in a Swiss-German sample of low back pain patients. Eur Spine J [Internet]. 2004 Jul [cited 2019 Oct 6];13(4). Available from: http://link.springer.com/10.1007/s00586-003-0663-3

32. Wand BM, James M, Abbaszadeh S, George PJ, Formby PM, Smith AJ, et al. Assessing self-perception in patients with chronic low back pain: Development of a back-specific body-perception questionnaire. J Back Musculoskelet Rehabil. 2014 Nov 5;27(4):463-73.

33. Bjelland I, Dahl AA, Haug TT, Neckelmann D. The validity of the Hospital Anxiety and Depression Scale. J Psychosom Res. 2002 Feb;52(2):69-77.

34. Snaith RP, Zigmond AS. The hospital anxiety and depression scale. BMJ. 1986 Feb 1;292(6516):344-344.

35. Boonstra AM, Schiphorst Preuper HR, Reneman MF, Posthumus JB, Stewart RE. Reliability and validity of the visual analogue scale for disability in patients with chronic musculoskeletal pain: Int J Rehabil Res. 2008 Jun;31(2):165-9.

36. R-Core-Team, 2015, R: a language and environment for statistical computing, In: R Foundation for Statistical Computing, Vienna, Austria. 2015.

37. Catley MJ, O’Connell NE, Berryman C, Ayhan FF, Moseley GL. Is Tactile Acuity Altered in People With Chronic Pain? A Systematic Review and Meta-analysis. J Pain. 2014 Oct;15(10):985-1000.

38. Ehrenbrusthoff K, Ryan CG, Grüneberg C, Wand BM, Martin DJ. The translation, validity and reliability of the German version of the Fremantle Back Awareness Questionnaire. Hilfiker R, editor. PLOS ONE. 2018 Oct 4;13(10):e0205244.

39. Nishigami T, Mibu A, Osumi M, Son K, Yamamoto S, Kajiwara S, et al. Are tactile acuity and clinical symptoms related to differences in perceived body image in patients with chronic nonspecific lower back pain? Man Ther. 2015 Feb;20(1):63-7.

40. Saragiotto BT, Maher CG, Yamato TP, Costa LO, Menezes Costa LC, Ostelo RW, et al. Motor control exercise for chronic non-specific lowback pain. Cochrane Back and Neck Group, editor. Cochrane Database Syst Rev [Internet]. 2016 Jan 8 [cited 2019 Oct 6]; Available from: http://doi.wiley.com/10.1002/14651858.CD012004

41. Rackwitz B, de Bie R, Limm H, von Garnier K, Ewert T, Stucki G. Segmental stabilizing exercises and low back pain. What is the evidence? A systematic review of randomized controlled trials. Clin Rehabil. 2006 Jul;20(7):553-67.

\section{Tables}


Table 1

Demographic characteristics

\begin{tabular}{|c|c|c|c|c|}
\hline \multirow[b]{2}{*}{ Variables } & \multicolumn{2}{|c|}{ CLBP group $(n=30)$} & \multicolumn{2}{|c|}{ Healthy control group $(n=30)$} \\
\hline & Mean & Range & Mean & Range \\
\hline Gender female / male & $15 / 15$ & & $15 / 15$ & \\
\hline Age (years) & 52.9 (SD 18.0) & $25.0-83.0$ & 51.8 (SD 16.5) & $22.0-79.0$ \\
\hline Weight (kg) & 81.3 (SD 18.0) & $50.0-122.0$ & 72.0 (SD 11.9) & $52.0-100.0$ \\
\hline Body height (cm) & 172.4 (SD 9.7) & $157.0-194.0$ & 173.1 (SD 8.7) & $155.0-186.0$ \\
\hline Body Mass Index & 27.4 (SD 5.8) & $16.9-44.6$ & 24.0 (SD 3.0) & $18.3-30.2$ \\
\hline Affected side (bilateral / left / right) & $17 / 3 / 10$ & & & \\
\hline Pain duration (months) & 131.8 (SD 160) & $3.0-660.0$ & & \\
\hline Pain intensity $(0-100)$ & 33.4 (SD 20) & $4.0-75.0$ & & \\
\hline RMDQ (0-24) & $8.2(\mathrm{SD} 4.1)$ & $4.0-21.0$ & 0.07 (SD 0.3) & $0.0-1.0$ \\
\hline
\end{tabular}

Table 2

Outcomes

\begin{tabular}{|c|c|c|c|c|}
\hline \multirow[b]{2}{*}{ Variables } & \multicolumn{2}{|c|}{ CLBP group $(n=30)$} & \multicolumn{2}{|c|}{ Healthy control group $(n=30)$} \\
\hline & Median & Range & Median & Range \\
\hline BPA deviation steps (0-4) & 2.0 (IQR 2.0) & $0.0-4.0$ & 2.0 (IQR 2.0) & $0.0-4.0$ \\
\hline BPA wider & \multicolumn{2}{|l|}{$18(60 \%)$} & \multicolumn{2}{|l|}{$16(53 \%)$} \\
\hline BPA slender & \multicolumn{2}{|l|}{$8(26.5 \%)$} & \multicolumn{2}{|l|}{$10(33.5 \%)$} \\
\hline BPA original & \multicolumn{2}{|l|}{$4(13.5 \%)$} & \multicolumn{2}{|l|}{$4(13.5 \%)$} \\
\hline TPD horizontal right (mm) & 65.0 (IQR 33.8) & $15.0-105.0$ & 67.5 (IQR 23.8) & $30.0-105.0$ \\
\hline TPD horizontal left (mm) & 67.5 (IQR 30.0) & $30.0-120.0$ & 57.5 (IQR 18.8) & $25.0-140.0$ \\
\hline TPD vertical right (mm) & 45.0 (IQR 20.0) & $20.0-110.0$ & 35.0 (IQR 33.8) & $15.0-85.0$ \\
\hline TPD vertical left (mm) & 42.5 (IQR 20.0) & $15.0-150.0$ & 35.0 (IQR 28.8) & $10.0-90.0$ \\
\hline $\mathrm{MCl}$ positive tests $(0-6)$ & 3.0 (IQR 2.0) & $1.0-5.0$ & 2.0 (IQR 1.0) & $0.0-5.0$ \\
\hline FABQ (0-96) & 33.0 (IQR 28.8) & $0.0-96.0$ & 1.0 (IQR 6.8) & $0.0-37.0$ \\
\hline HADS (0-42) & 9.0 (IQR 5.5) & $0.0-17.0$ & 3.5 (IQR 5.8) & $0.0-16.0$ \\
\hline FreBaQ (0-36) & 7.0 (IQR 6.8) & $0.0-22.0$ & 0.0 (IQR 2.0) & $0.0-8.0$ \\
\hline \multicolumn{5}{|c|}{$\begin{array}{l}\text { BPA: Back-Photo Assessment, TPD: Two-Point Discrimination, MCl: movement control impairment } \\
\text { MCl: movement control impairment, FABQ: Fear Avoidance Belief Questionnaire } \\
\text { HADS: Hospital Anxiety and Depression Scale, FreBaQ: Fremantle Back Awareness Questionnaire } \\
\text { FreBaQ: Fremantle Back Awareness Questionnaire }\end{array}$} \\
\hline
\end{tabular}


Table 3

Multiple logistic regression

\begin{tabular}{|lllllll|}
\hline Variables & coef & exp(coef) & se(coef) & z & $\operatorname{Pr}(>|z|)$ & $95 \% \mathrm{Cl}$ \\
\hline BPA & -0.300512 & 0.7404 & 0.29043 & -1.03473 & 0.30079 & $0.4191-1.308$ \\
\hline TPD horizontal right & 0.009997 & 1.0100 & 0.02481 & 0.40292 & 0.68701 & $0.9621-1.060$ \\
\hline TPD horizontal left & -0.015363 & 0.9848 & 0.02734 & -0.56185 & & $0.9334-1.039$ \\
\hline TPD vertical right & 0.029290 & 1.0297 & 0.03171 & 0.92365 & 0.35567 & $0.9677-1.096$ \\
\hline TPD vertical left & 0.001855 & 1.0019 & 0.02318 & 0.08003 & 0.93621 & $0.9574-1.048$ \\
\hline MCl & 0.651199 & 1.9178 & 0.33215 & 1.96055 & 0.04993 & $1.0002-3.677$ \\
\hline BPA: Back-Photo Assessment, TPD: Two-Point Discrimination, MCl: movement control impairment \\
\hline
\end{tabular}

Table 4

Spearman correlations

\begin{tabular}{|c|c|c|c|c|c|c|c|c|c|c|c|c|c|}
\hline Variables & $\begin{array}{l}\text { TPD h } \\
\text { right }\end{array}$ & $\begin{array}{l}\text { TPD h } \\
\text { left }\end{array}$ & $\begin{array}{l}\text { TPD v } \\
\text { right }\end{array}$ & $\begin{array}{l}\text { TPD } \\
v \text { left }\end{array}$ & $\mathrm{MCl}$ & FreBAQ & FABQ & HADS & Age & $\begin{array}{l}\text { Body } \\
\text { height }\end{array}$ & $\begin{array}{l}\text { Body } \\
\text { weight }\end{array}$ & BMI & BPA \\
\hline $\begin{array}{l}\text { TPD h } \\
\text { right }\end{array}$ & 1.000 & 0.790 & 0.408 & 0.318 & -0.136 & 0.022 & -0.026 & 0.077 & 0.296 & 0.049 & 0.458 & 0.454 & 0.232 \\
\hline $\begin{array}{l}\text { TPD h } \\
\text { left }\end{array}$ & 0.790 & 1.000 & 0.591 & 0.580 & -0.092 & 0.086 & 0.080 & 0.112 & 0.375 & 0.026 & 0.422 & 0.437 & 0.262 \\
\hline $\begin{array}{l}\text { TPD v } \\
\text { right }\end{array}$ & 0.408 & 0.591 & 1.000 & 0.847 & -0.086 & 0.225 & 0.165 & 0.197 & 0.207 & 0.036 & 0.123 & 0.178 & 0.170 \\
\hline $\begin{array}{l}\text { TPD v } \\
\text { left }\end{array}$ & 0.318 & 0.580 & 0.847 & 1.000 & 0.009 & 0.172 & 0.166 & 0.021 & 0.047 & 0.051 & 0.106 & 0.149 & 0.248 \\
\hline $\mathrm{MCl}$ & -0.136 & -0.092 & -0.086 & 0.009 & 1.000 & 0.223 & 0.227 & 0.055 & -0.206 & 0.222 & 0.247 & 0.140 & 0.086 \\
\hline FreBAQ & 0.022 & 0.086 & 0.225 & 0.172 & 0.223 & 1.000 & 0.711 & 0.575 & -0.162 & -0.206 & 0.100 & 0.221 & -0.093 \\
\hline FABQ & -0.026 & 0.080 & 0.165 & 0.166 & 0.227 & 0.711 & 1.000 & 0.592 & -0.129 & -0.123 & 0.042 & 0.116 & -0.080 \\
\hline HADS & 0.077 & 0.112 & 0.197 & 0.021 & 0.055 & 0.575 & 0.592 & 1.000 & 0.203 & -0.077 & 0.199 & 0.271 & 0.070 \\
\hline Age & 0.296 & 0.375 & 0.207 & 0.047 & -0.206 & -0.161 & -0.129 & 0.203 & 1.000 & -0.179 & 0.166 & 0.281 & 0.148 \\
\hline $\begin{array}{l}\text { Body } \\
\text { height }\end{array}$ & 0.049 & 0.026 & 0.036 & 0.051 & 0.222 & -0.206 & -0.123 & -0.077 & -0.179 & 1.000 & 0.463 & -0.026 & 0.001 \\
\hline $\begin{array}{l}\text { Body } \\
\text { weight }\end{array}$ & 0.458 & 0.422 & 0.123 & 0.106 & 0.247 & 0.100 & 0.042 & 0.199 & 0.166 & 0.463 & 1.000 & 0.845 & 0.294 \\
\hline BMI & 0.454 & 0.437 & 0.178 & 0.149 & 0.140 & 0.221 & 0.116 & 0.271 & 0.281 & -0.026 & 0.845 & 1.000 & 0.350 \\
\hline BPA & 0.232 & 0.262 & 0.170 & 0.248 & 0.086 & -0.093 & -0.080 & 0.070 & 0.148 & 0.001 & 0.294 & 0.350 & 1.000 \\
\hline
\end{tabular}

\section{Figures}



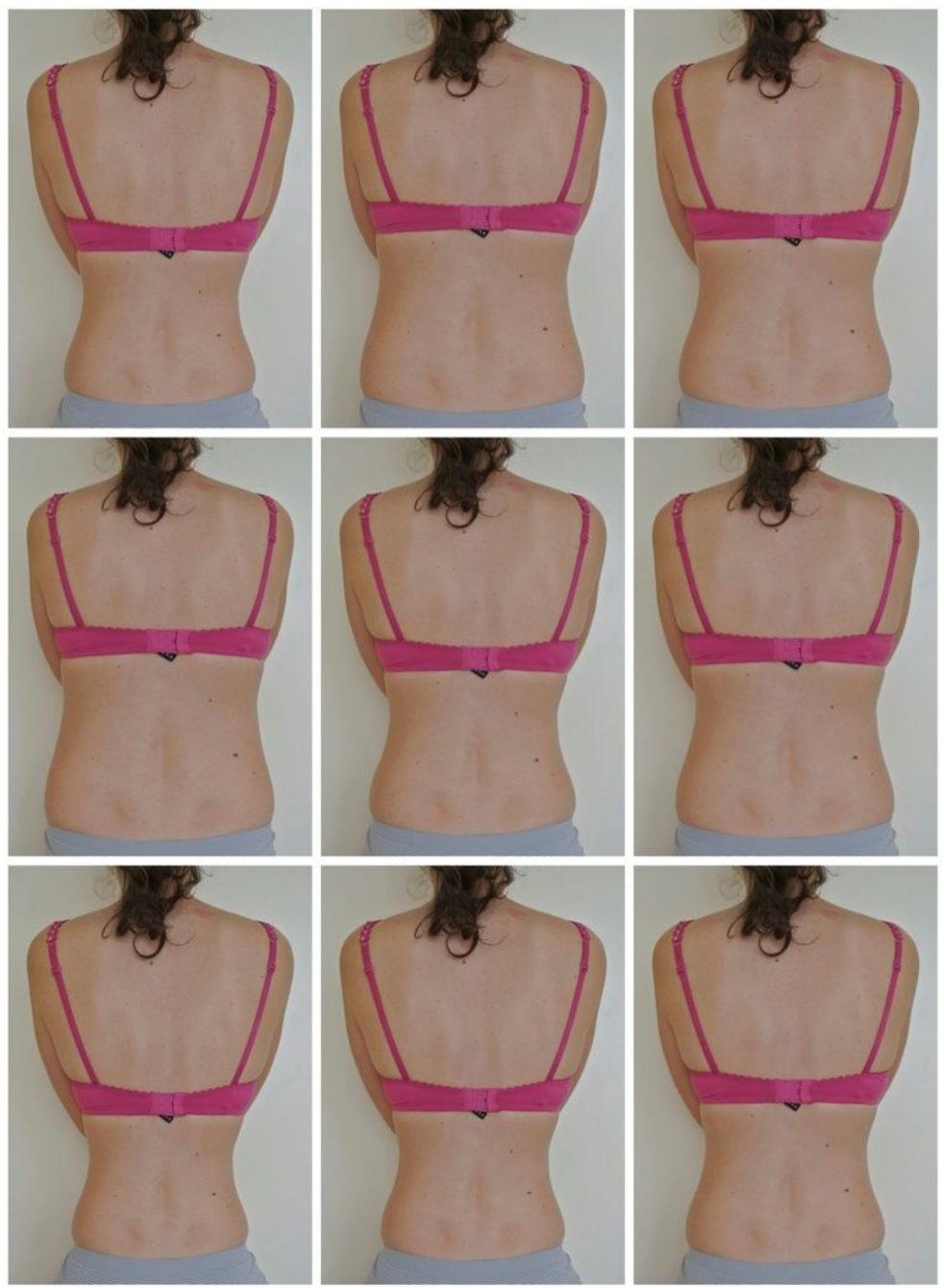

Back photo example

Order of the photos: $3(-6 \%), 8(+9 \%), 6(+3 \%), 9(+12 \%), 5$ (original),

$7(+6 \%), 1(-12 \%), 2(-9 \%), 4(-3 \%)$

\section{Figure 1}

Back photo example BPA test. 

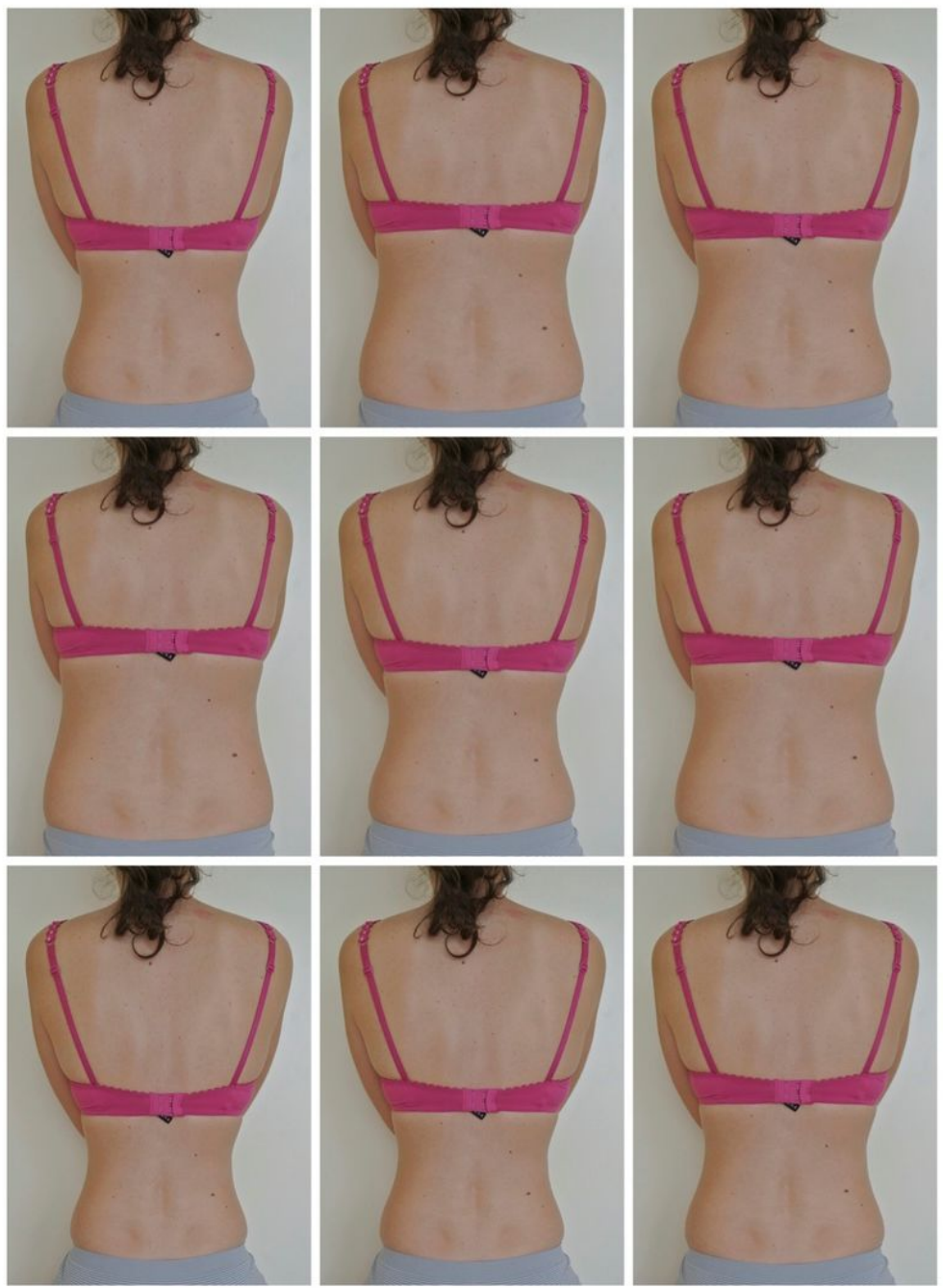

Back photo example

Order of the photos: $3(-6 \%), 8(+9 \%), 6(+3 \%), 9(+12 \%), 5$ (original),

$7(+6 \%), 1(-12 \%), 2(-9 \%), 4(-3 \%)$

\section{Figure 1}

Back photo example BPA test. 


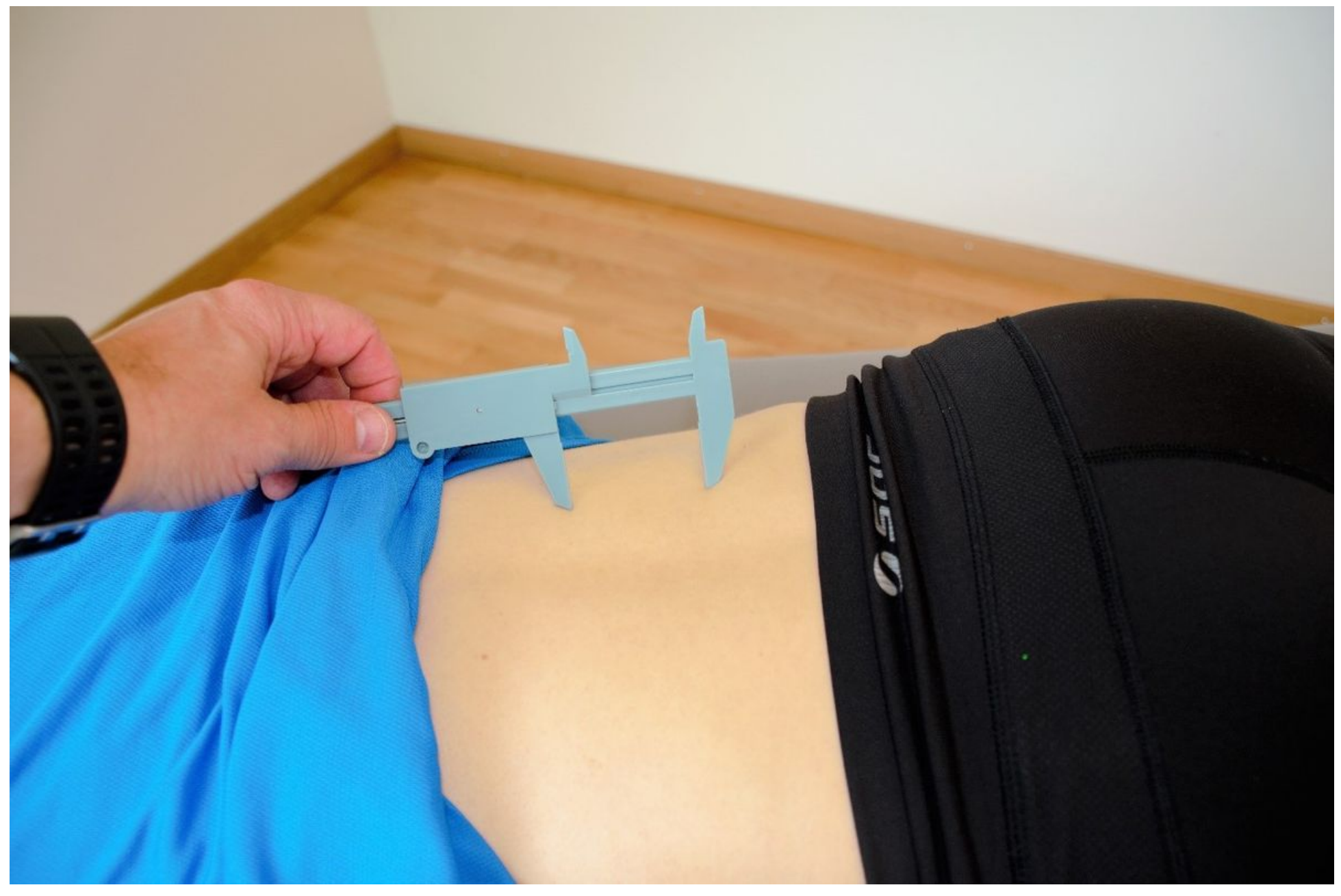

\section{Figure 2}

Two point discrimination (TPD) test. 


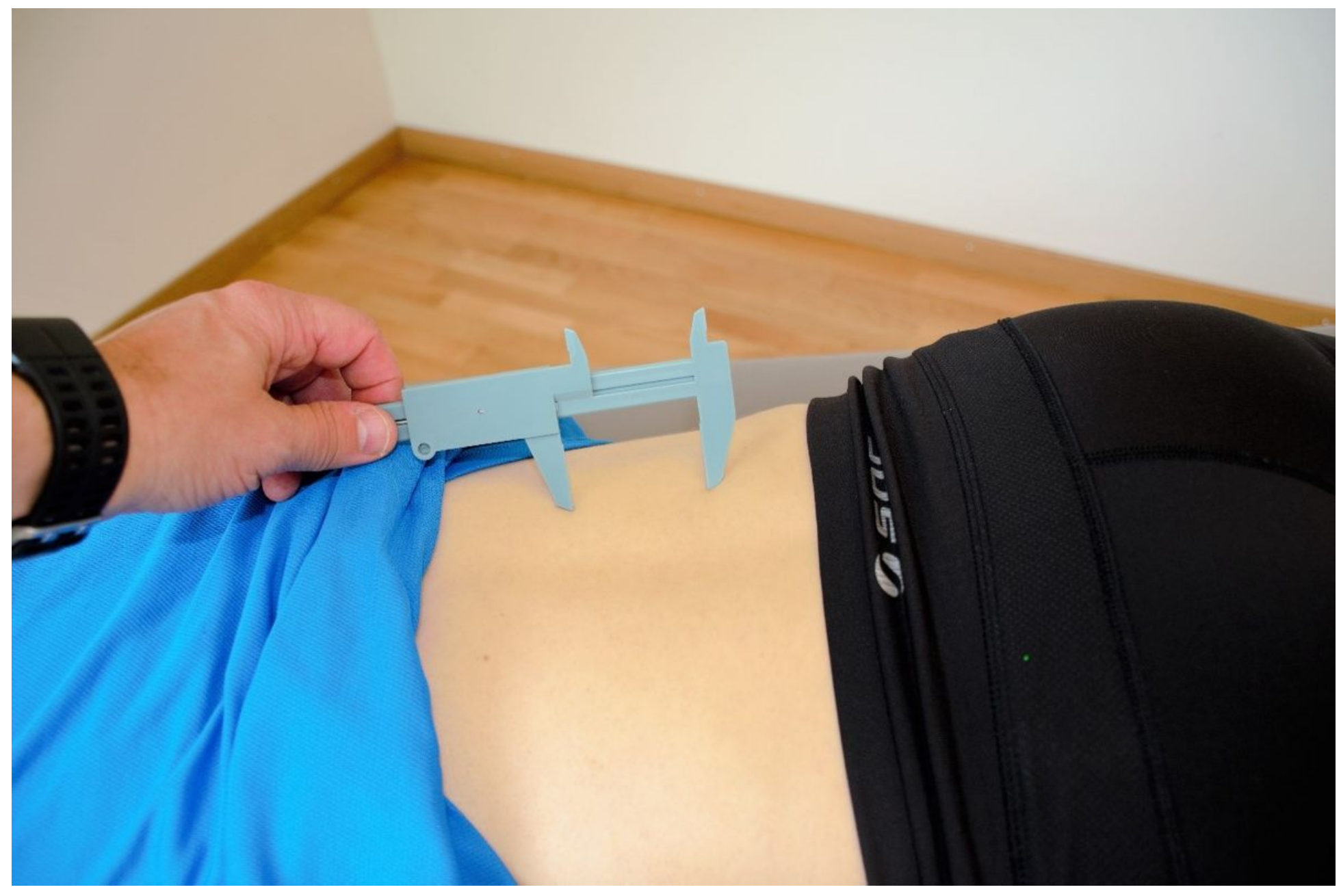

\section{Figure 2}

Two point discrimination (TPD) test. 

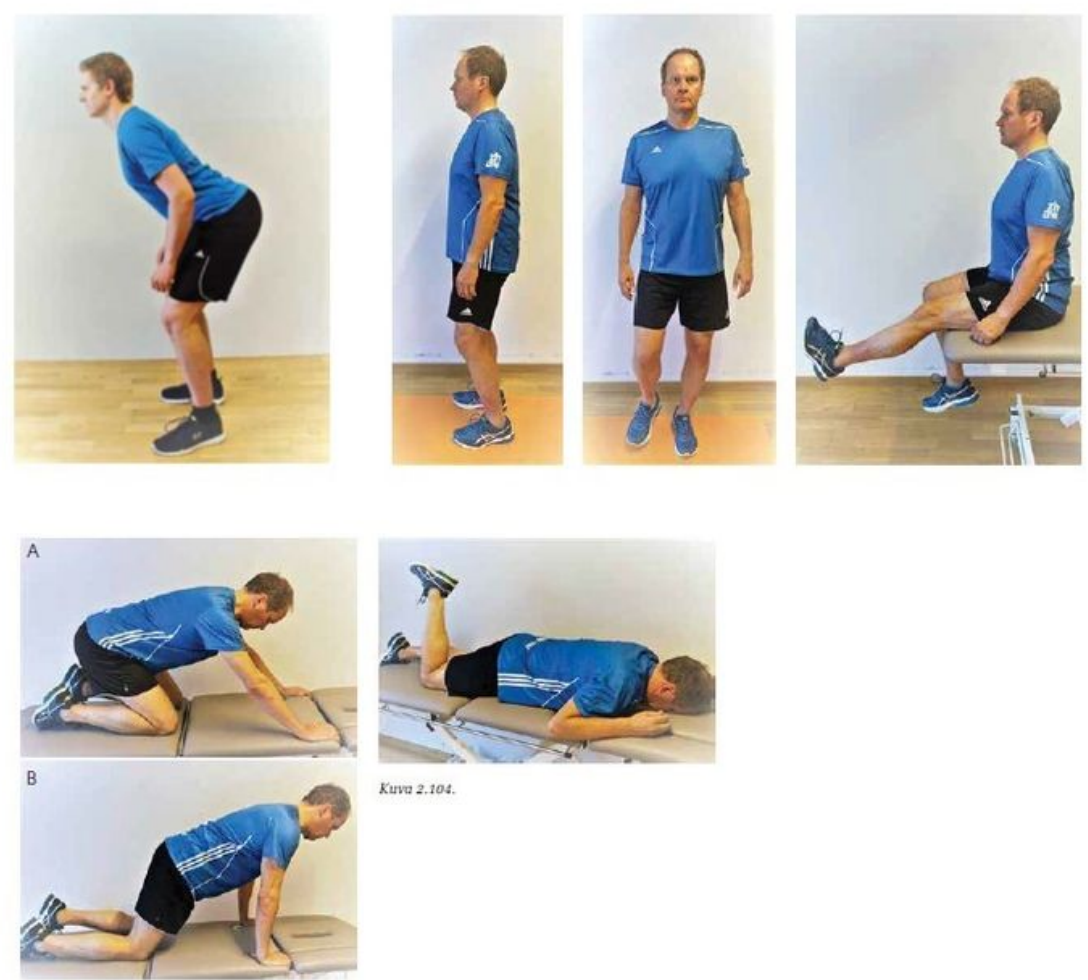

Kuva 2.104

Figure 3

Movement control tests (MCT)
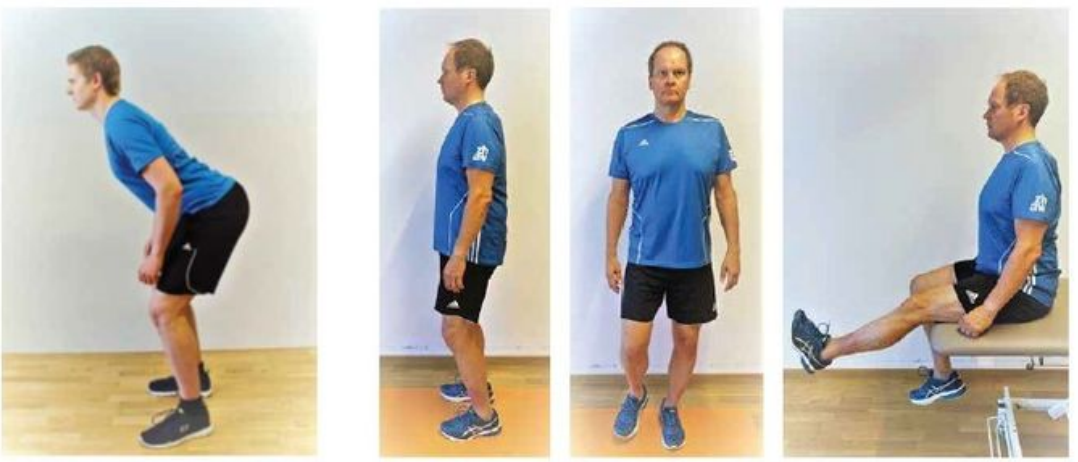

\section{Movement control tests}

\section{- Low Back}

1. Waiters bow

2. Pelvic tilt

3. One leg stance

4. Sitting knee extension

5. Four point kneeling

6. Prone knee bend

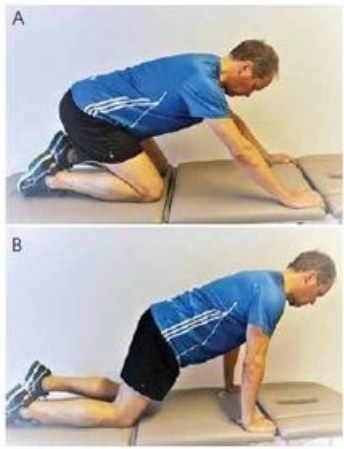

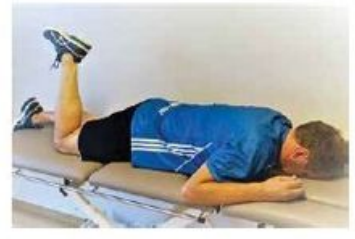

Kuvv 2.104.

Figure 3 
Boxplots of the main variables
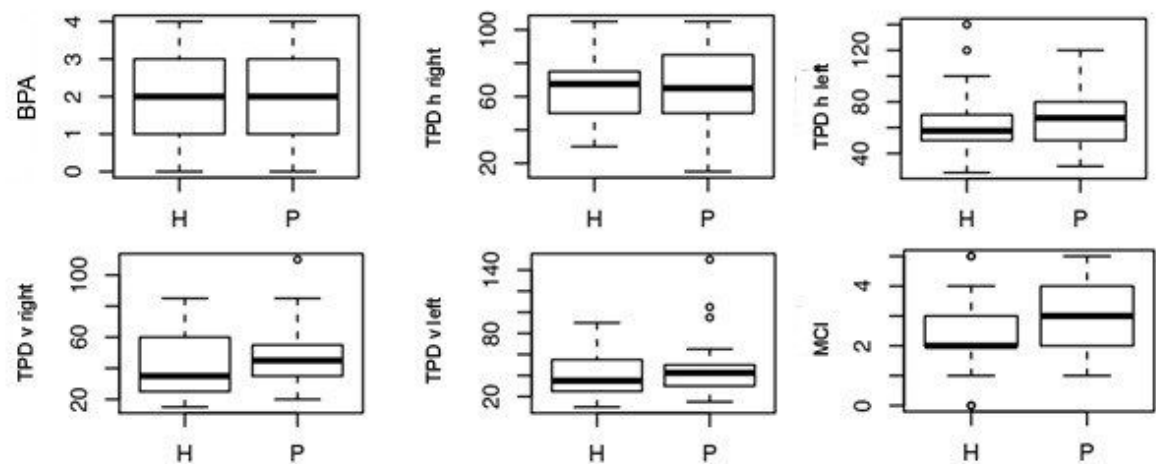

\section{Figure 4}

Group differences H: healthy controls, P: patients, BPA: Back-Photo Assessment, TPD v: Two-Point Discrimination vertical, TPD h: Two-Point Discrimination horizontal, MCl: movement control impairment

Boxplots of the main variables
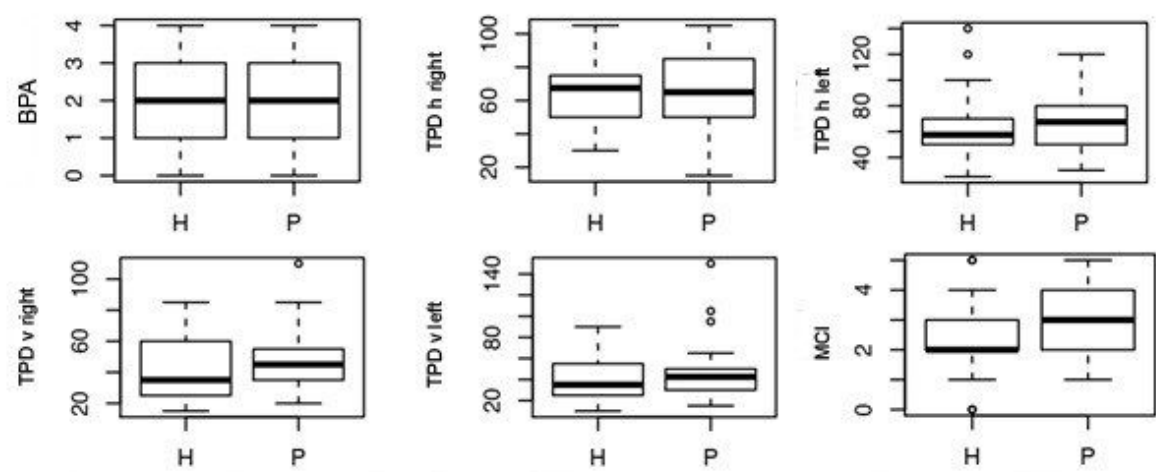

\section{Figure 4}

Group differences H: healthy controls, P: patients, BPA: Back-Photo Assessment, TPD v: Two-Point Discrimination vertical, TPD h: Two-Point Discrimination horizontal, MCl: movement control impairment 
Boxplots of the questionnaires
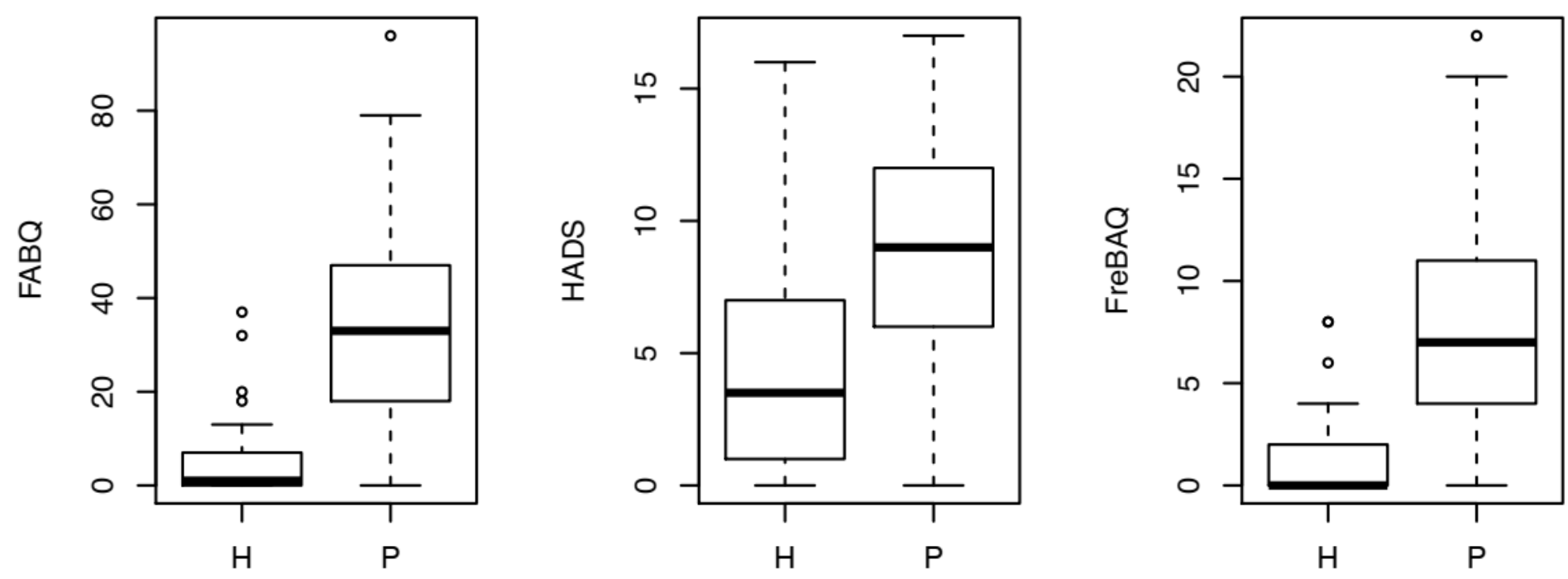

$\mathrm{H}$ : healthy group, $\mathrm{P}$ : patient group, FABQ: Fear Avoidance Belief Questionnaire, HADS: Hospital Anxiety and Depression Scale, FreBAQ: Fremantle Back Awareness Questionnaire

Figure 5

Group differences in questionnaires H: healthy controls, P: patients, FABQ: Fear Avoidance Belief Questionnaire, HADS: Hospital Anxiety and Depression Scale, FreBaQ: Fremantle Back Awareness Questionnaire

Boxplots of the questionnaires
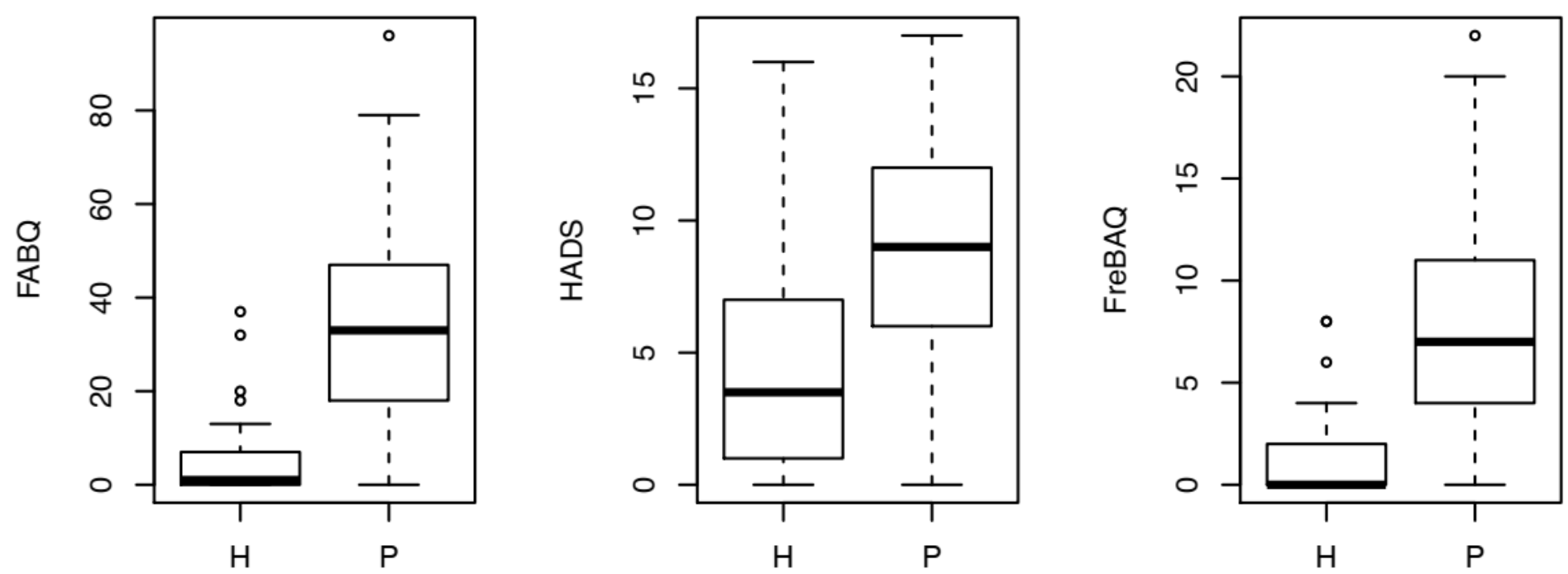

$\mathrm{H}$ : healthy group, P: patient group, FABQ: Fear Avoidance Belief Questionnaire, HADS: Hospital Anxiety and Depression Scale, FreBAQ: Fremantle Back Awareness Questionnaire

Figure 5

Group differences in questionnaires H: healthy controls, P: patients, FABQ: Fear Avoidance Belief Questionnaire, HADS: Hospital Anxiety and Depression Scale, FreBaQ: Fremantle Back Awareness Questionnaire 